\title{
Evaluation and Classification of the Dummy Loadings Regarding Biomechanical Protection Criteria during a Bus Rollover
}

\author{
M. Kalinský* \& J. Pavlata \\ Engineering Department, TÜV SÜD Auto CZ, Prague, Czech Republic, \\ * Corresponding author: michal.kalinsky@tuv-sud.cz
}

\begin{abstract}
This paper presents simulation experiments and follow-up investigations of the passengers' biomechanical criteria during the rollover of various types of busses. The evaluation process focuses mainly on the reduction of the risk of injury. The partial aim is to indicate the influence of the safety restraint systems.
\end{abstract}

KEY WORDS: Bus rollover, bus crash, simulation, passive safety, biomechanical criteria, HIC, ECE R66.

\section{INTRODUCTION}

Today's road traffic is characterized by its high density. Under extreme traffic density conditions, the drivers' failure rate increases, and such mistakes often result in dangerous collisions. The most dangerous accidents, with respect to the passengers' injuries and fatalities, are accidents with buses, especially rollover. The Czech police statistics show that about 35 passengers have died and over 200 have been injured due to bus accidents since 2005.

For these reasons a high importance is paid to enhance the active and passive safety of the vehicles. These significant trends are particularly applicable to the development of the mass public transport means. Mandatory homologation of the new bus types leads to progressive increase of the passengers' safety, and the regulation ECE R66 was therefore introduced in 1986. This regulation forces the bus manufacturers to guarantee sufficient strength and stiffness of bus superstructures. Standing bus rolls over from a tilting platform, which is $80 \mathrm{~cm}$ above a flat ground. In fact no interior part of the vehicle may perforate into the so called residual space (a space inside the bus designed to keep passengers safe) during the rollover to prevent any excessive injury risk to the passengers. A couple of approaches to check the bus superstructure are described in ECE R66. Besides the real rollover test, which is very expensive, there is a possibility to substitute it with a numerical simulation.

TÜV SÜD Auto CZ is, among its other activities, traditionally focused on the evaluation of strength and stiffness of bus structures in the case of rollover. The evaluation is performed using real crash-tests and by numerical simulation methods. The experience acquired from these tests and virtual simulations make TÜV SÜD Auto CZ an appropriate subject to design passive safety solutions.

This paper is concerned with the investigation of the passengers' biomechanical criteria during the rollover of the bus. Three different types of buses were chosen to represent 
the construction classes (MI, MII, MIII). Another aim is to determine the influence of the restraint safety systems on the passengers' safety.

\section{MATHEMATICAL MODELLING CONDITIONS}

In the first phase the question of the simulation time and range to monitor the passenger behavior during the rollover was solved. The results were compared on a particular part of the bus chassis structure including the seats and dummy models. Another aim was to tune the model attributes in accordance with the passengers' behavior inside the vehicle.

In the next stage the typical representatives of the bus classes were chosen to perform the rollover simulation. Passengers' behavior in different types of buses was compared with each other. The bus types are represented by the coach, the suburban bus and the city bus.

Methodology of the rollover process has been acquired from ECE R66 regulation. The simulation experiments were performed in PAM-CRASH/SAFE software by Mecas-ESI. The ARB Hybrid HIII 50\% dummy model was used for all the simulations.

\subsection{Determination of the simulation range}

The partial aim of the project was to set the duration of the entire simulation of the bus rollover. To accomplish these conditions a model of the segment of the bus chassis with a seat and a belted dummy was created and two simulations were performed; a simulation with the roll-up phase and a simulation without the roll-up phase (the second simulation began in the point of unstable equilibrium position).

No significant difference in either the dummy or the chassis behavior was found from the comparison of the aforementioned simulations. The starting point of the following simulations was determined as the point of unstable equilibrium position of the vehicle (see Figure 1).

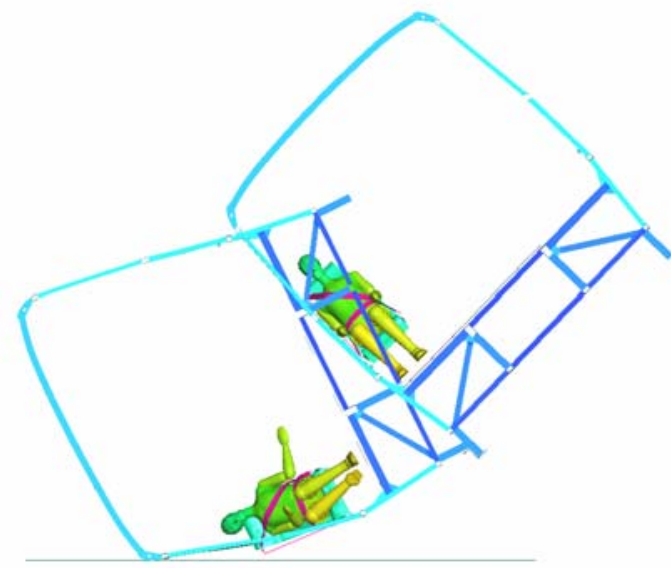

Figure 1: Rollover of the chassis segment - unstable equilibrium position

\subsection{Validation with experimental simulation and verification}

\subsubsection{Rollover simulation of the chassis segment}

The simulation of the rollover of the chassis segment is the final test, which are designed for tuning the material properties. The results of the final test are verified by rollover of the real segment prototype. 
The material properties were verified using a comparison of the simulation and the real test of the chassis segment. The whole process of the real test was recorded with a high-speed camera. Selected important points were marked on the structure of the segment (see Figure 2).

The motion of these points was analyzed from the camera record and compared with the simulation. The residual deformation of the segment was measured after the rollover test. Figure 2 presents the results of the simulation compared to the high-speed camera record. The situation at $170 \mathrm{~ms}$ is displayed, which represents the highest deformation of the segment.

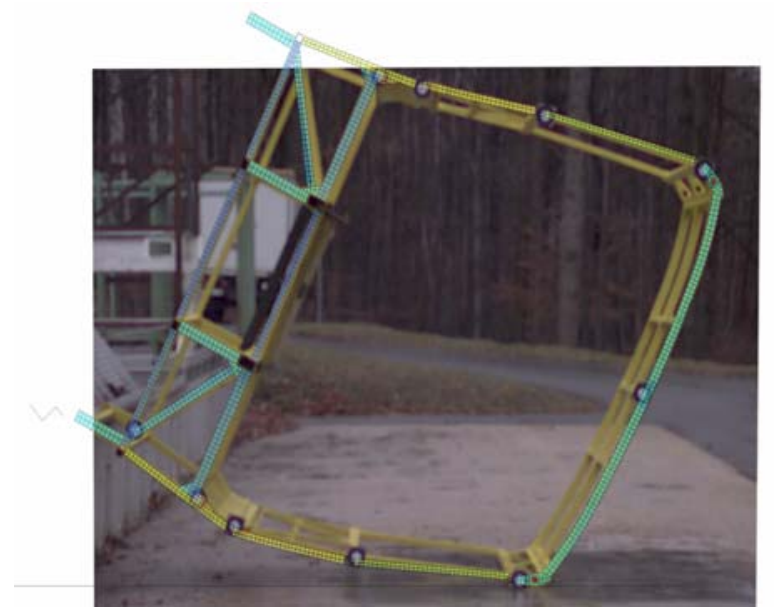

\section{Figure 2: Highest deformation comparison (simulation vs. real test)}

2.2.2 Tuning the model features with respect to the passenger behavior in the vehicle interior.

A couple of pre-simulations were performed in order to acquire the information of the dummy behavior when interacting with the vehicle interior, especially with the seat cushion. These pre-simulations help us to determine the seat cushion properties by the interaction between the dummy and the seat in the gravity field (see Figure 3). The material properties of the seat cushion were afterwards adjusted to correspond with the strength and stiffness of the real seat cushion on one hand, and to maintain the numerical stability of the simulations on the other hand.
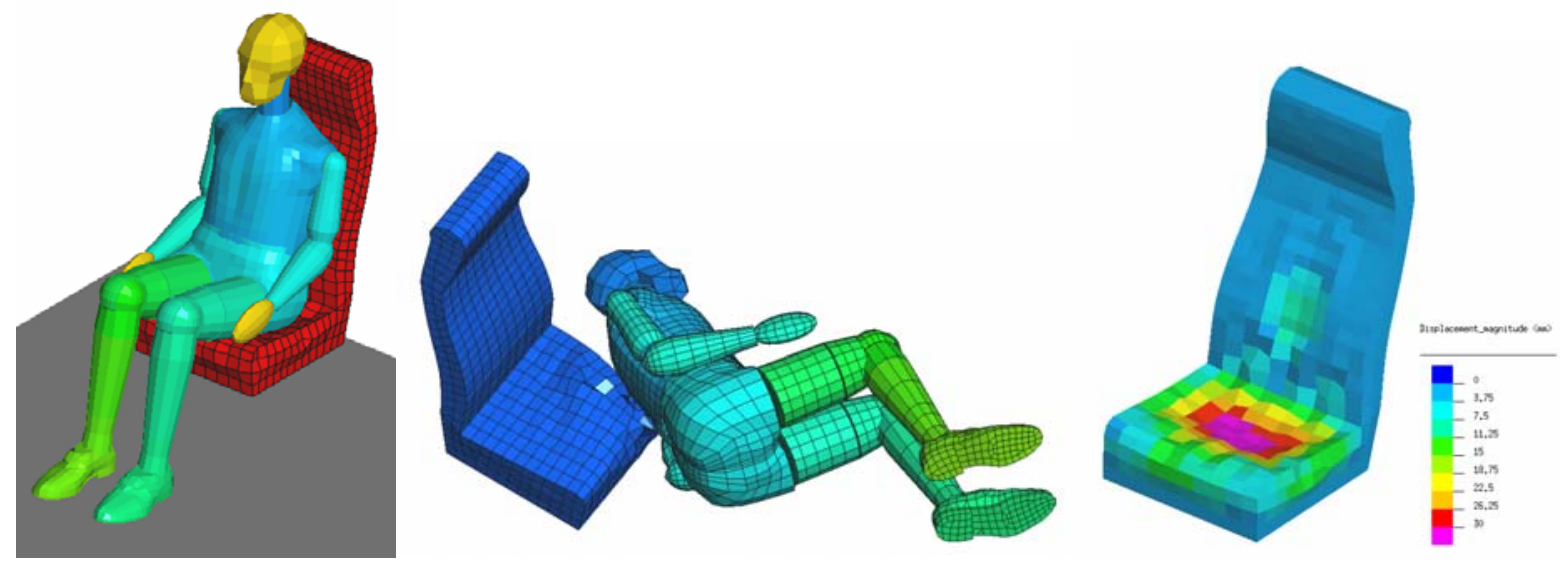

Figure 3: Properties tuning of the seat cushion 


\subsection{FE models of the representative bus classes}

Three representative bus types were chosen to monitor the behavior of the passengers during the rollover:

Coach (category M3/III) see Figure 4

Suburban bus (category M3/II) see Figure 5

City bus (lowdecker) (category M3/I) see Figure 6

The models were prepared for the virtual calculation according to the methodology described in ECE 66 regulation and EC 2001/85 directive. The Krupkowsky elastic-plastic material definition was used to describe the chassis material behavior.

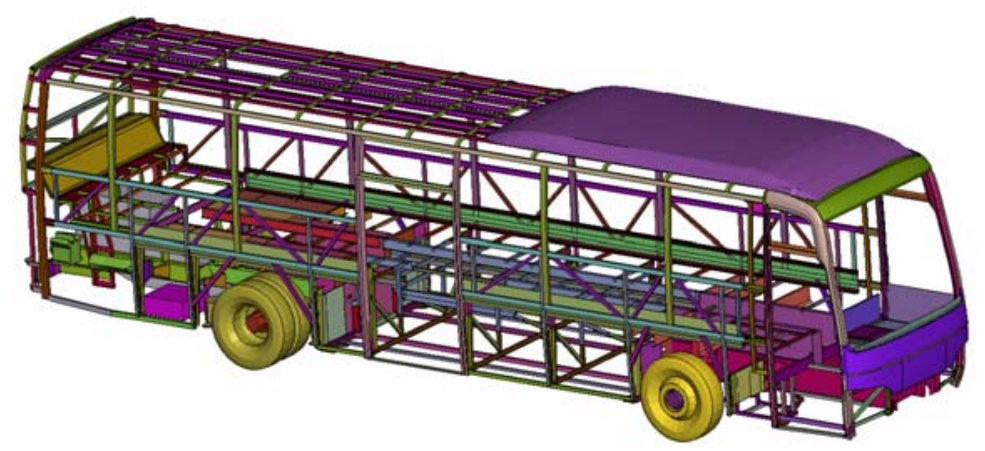

Figure 4: FE model of the coach

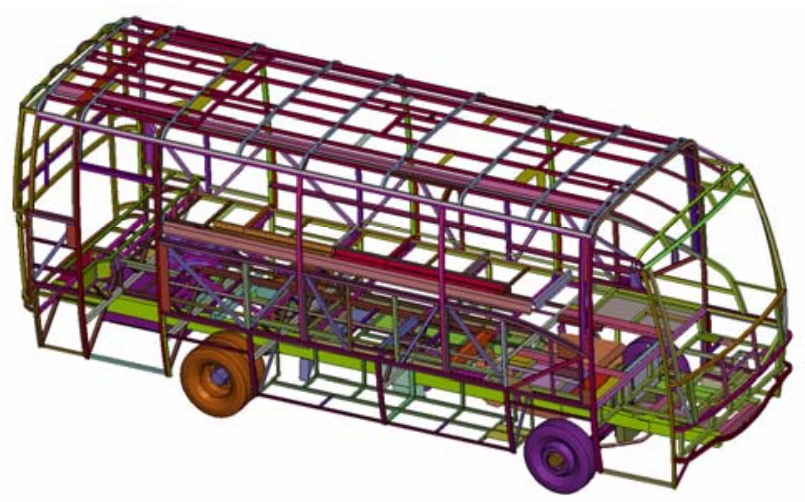

Figure 5: FE model of the suburban bus

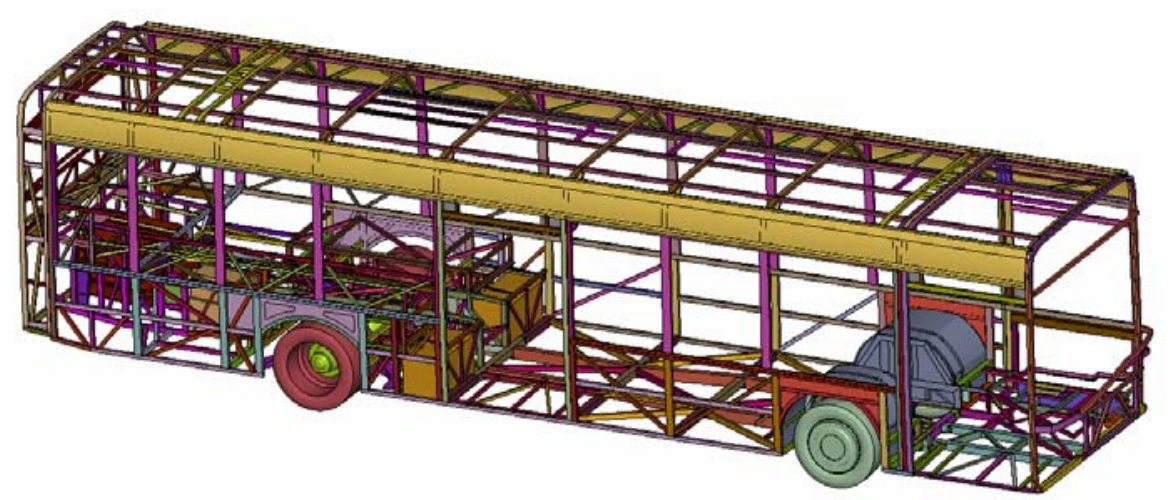

Figure 6: FE model of the city bus (lowdecker) 


\subsection{Calculation definition}

The starting point of the simulations was set as the point of the unstable equilibrium position of the vehicle on the tilting platform. The passengers are seated in their initial position, i.e., their seats. The bus rolls over in the gravity field until it interacts with the ground, then the deformation of the bus structure follows. The total time of the simulation was set to 2500 ms. The aim of the simulations was to analyze the biomechanical loading of the passengers. The standard Head Injury Criterion (HIC15) is chosen to evaluate the head loading and the 3ms criteria are applied for thorax and pelvis of the dummies. HIC15 was evaluated from the CFC1000 filtered resultant acceleration of the dummy's head.

\subsection{Passengers’ arrangement}

The passengers were arranged with the respect to the vehicle disposition, to monitoring possibilities of their behavior and to the simulation complexity. Therefore the passengers are seated in pairs or single in various rows, and also on both sides of the aisle to analyze the influence of the tilting direction. Figure 7 presents an example of the passenger arrangement.

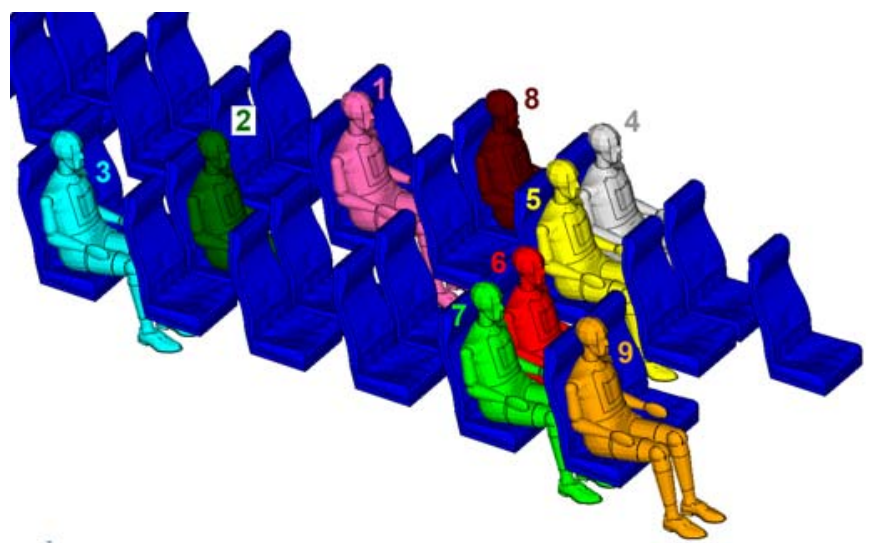

Figure 7: Seating of passengers in the coach

\section{RESULTS}

Figure 8 shows the final situation, after the interaction with the ground and the following deformation of the bus structure. The rotational impact velocity of the bus structure reaches the peak value of $5.1 \mathrm{~m} / \mathrm{s}$.

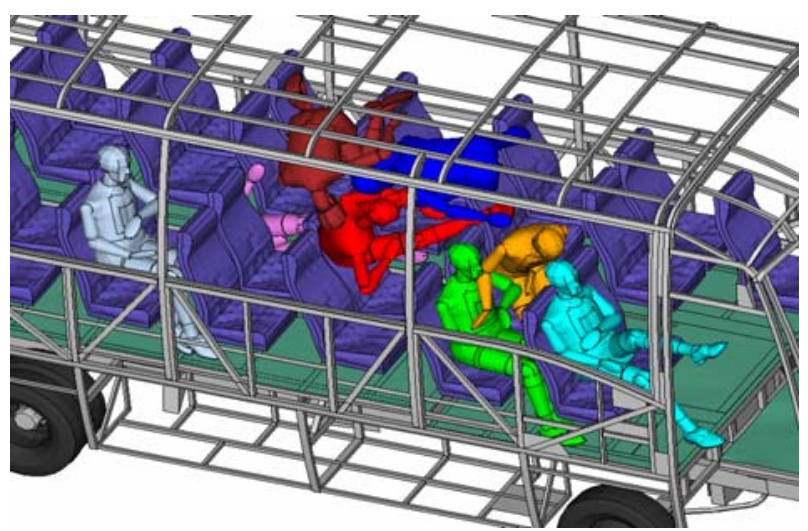

Figure 8: Rollover of the suburban bus 


\subsection{Data analysis}

The maximum values of the biomechanical loading of the unbelted dummies are presented in Table 1, as well as the peak values of HIC15 and both thorax and pelvis 3ms criteria.

Tab.1 Maximum values of the biomechanical loading of the unbelted dummies

\begin{tabular}{|c|c|c|c|c|c|c|}
\hline \multicolumn{7}{|c|}{ City bus (lowdecker) } \\
\hline \multirow[b]{2}{*}{ Dummy } & \multicolumn{2}{|c|}{ Head } & \multicolumn{2}{|c|}{ Thorax } & \multicolumn{2}{|c|}{ Pelvis } \\
\hline & HIC15 & $\begin{array}{l}\text { time } \\
{[\mathrm{ms}]}\end{array}$ & $\begin{array}{c}3 \text { ms max. } \\
\text { [g] }\end{array}$ & $\begin{array}{l}\text { Time } \\
\text { [ms] }\end{array}$ & $\begin{array}{c}3 \text { ms max. } \\
\text { [g] }\end{array}$ & $\begin{array}{l}\text { time } \\
\text { [ms] }\end{array}$ \\
\hline \multirow{2}{*}{$\begin{array}{l}\text { Maximum } \\
\text { values }\end{array}$} & 6446 & 791 & 38 & 1831 & 34 & 2221 \\
\hline & 6642 & 2075 & 36 & 1876 & 35 & 2075 \\
\hline & \multicolumn{6}{|c|}{ Suburban bus } \\
\hline \multirow[b]{2}{*}{ Dummy } & \multicolumn{2}{|c|}{ Head } & \multicolumn{2}{|c|}{ Thorax } & \multicolumn{2}{|c|}{ Pelvis } \\
\hline & HIC15 & $\begin{array}{l}\text { time } \\
\text { [ms] }\end{array}$ & $\begin{array}{c}3 \text { ms max. } \\
\text { [g] }\end{array}$ & $\begin{array}{l}\text { time } \\
\text { [ms] }\end{array}$ & $\begin{array}{c}3 \text { ms max. } \\
{[\mathrm{g}]}\end{array}$ & $\begin{array}{l}\text { time } \\
\text { [ms] }\end{array}$ \\
\hline \multirow{3}{*}{$\begin{array}{l}\text { Maximum } \\
\text { values }\end{array}$} & 8629 & 2291 & 61 & 2298 & 42 & 2299 \\
\hline & 5607 & 1993 & 50 & 467 & 45 & 2291 \\
\hline & \multicolumn{6}{|c|}{ Coach } \\
\hline \multirow[b]{2}{*}{ Dummy } & \multicolumn{2}{|c|}{ Head } & \multicolumn{2}{|c|}{ Thorax } & \multicolumn{2}{|c|}{ Pelvis } \\
\hline & HIC15 & $\begin{array}{l}\text { time } \\
{[\mathrm{ms}]}\end{array}$ & $\begin{array}{c}3 \text { ms max. } \\
\text { [g] }\end{array}$ & $\begin{array}{l}\text { time } \\
\text { [ms] }\end{array}$ & $\begin{array}{c}3 \text { ms max. } \\
{[\mathrm{g}]}\end{array}$ & $\begin{array}{l}\text { time } \\
\text { [ms] }\end{array}$ \\
\hline \multirow{2}{*}{$\begin{array}{c}\text { Maximum } \\
\text { values }\end{array}$} & 8041 & 411 & 54 & 998 & 38 & 588 \\
\hline & 8972 & 570 & 115 & 570 & 50 & 573 \\
\hline
\end{tabular}

\subsection{Range of the safety restraint systems application}

The virtual calculations of the bus rollover with the two point safety belts application were performed with all the three bus types. The maximum axial force in the safety belts was included in the results. The calculations of the bus rollover with the three point safety belt application were performed with the coach and the suburban bus. Unlike the previous calculations the model city bus is not considered here. The manner in which the city buses are utilized, is not compatible with the application of the three point safety belts, with respect to high passenger flow rate requirement.

The aforementioned virtual calculations were completed with the calculation of the city bus rollover focusing on the biomechanical criteria evaluation of disabled persons.

\subsection{Two point safety belts}

Figure 9 presents the final positions of the rolled over city bus. The maximum values of the biomechanical loading of the two point belted dummies are presented in Table 2, as well as the peak values of HIC15 and both thorax and pelvis 3ms criteria. 

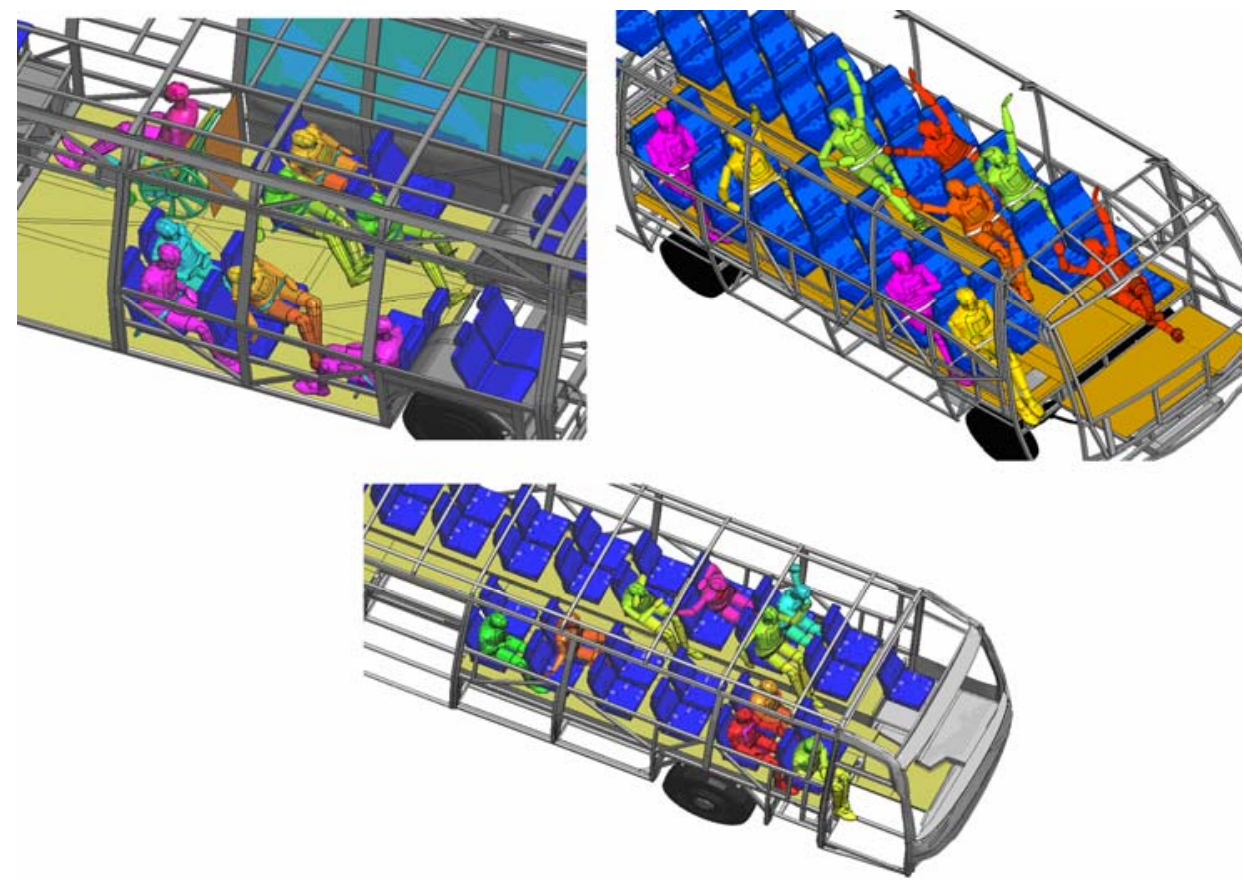

Figure 9: Rollover of the buses - two point safety belts

Tab. 2 Maximum values of the biomechanical loading of the dummies - two point safety belts

\begin{tabular}{|c|c|c|c|c|c|c|c|c|}
\hline \multicolumn{9}{|c|}{ City bus } \\
\hline \multirow[b]{2}{*}{ Dummy } & \multicolumn{2}{|c|}{ Head } & \multicolumn{2}{|c|}{ Thorax } & \multicolumn{2}{|c|}{ Pelvis } & \multicolumn{2}{|c|}{ Belts } \\
\hline & HIC15 & $\begin{array}{l}\text { time } \\
{[\mathrm{ms}]}\end{array}$ & $\begin{array}{c}3 \text { ms } \\
\max \\
{[\mathrm{g}]}\end{array}$ & $\begin{array}{l}\text { time } \\
\text { [ms] }\end{array}$ & $\begin{array}{c}3 \text { ms } \\
\max \\
{[\mathrm{g}]}\end{array}$ & $\begin{array}{l}\text { time } \\
{[\mathrm{ms}]}\end{array}$ & $\begin{array}{l}\text { force } \\
{[\mathrm{kN}]}\end{array}$ & $\begin{array}{l}\text { time } \\
{[\mathrm{ms}]}\end{array}$ \\
\hline \multirow{5}{*}{$\begin{array}{l}\text { Maximum } \\
\text { values }\end{array}$} & 359 & 1916 & 48 & 1917 & 23 & 1924 & 1,478 & 2010 \\
\hline & 123 & 1920 & 20 & 2011 & 13 & 1954 & 1,04 & 2090 \\
\hline & 5 & 1963 & 7 & 1999 & 8 & 2000 & 2,569 & 2010 \\
\hline & 5 & 1964 & 10 & 1996 & 10 & 1997 & 3,213 & 2000 \\
\hline & \multicolumn{8}{|c|}{ Suburban bus } \\
\hline \multirow{5}{*}{$\begin{array}{l}\text { Maximum } \\
\text { values }\end{array}$} & 1692 & 2092 & 15 & 2092 & 10 & 1964 & 0,818 & 1935 \\
\hline & 4081 & 2350 & 31 & 2350 & 19 & 1920 & 4,096 & 1935 \\
\hline & 186 & 1922 & 22 & 1923 & 34 & 1920 & 3,370 & 1945 \\
\hline & 23 & 1894 & 10 & 1937 & 12 & 1957 & 3,892 & 1935 \\
\hline & \multicolumn{8}{|c|}{ Coach } \\
\hline \multirow{4}{*}{$\begin{array}{l}\text { Maximum } \\
\text { values }\end{array}$} & 3616 & 1802 & 11 & 1706 & 14 & 1706 & 5,760 & 1760 \\
\hline & 153 & 1802 & 24 & 1802 & 17 & 1802 & 5,212 & 1750 \\
\hline & 52 & 1684 & 38 & 1685 & 20 & 2097 & 3,638 & 2120 \\
\hline & 106 & 1685 & 30 & 1684 & 20 & 2077 & 1,479 & 2090 \\
\hline
\end{tabular}




\subsection{Three point safety belts}

Figure 10 shows the final positions of the rolled over coach and suburban bus. The maximum values of the biomechanical loading of the three point belted dummies are presented in Table 3 as well as the peak values of HIC15 and both thorax and pelvis 3ms criteria.
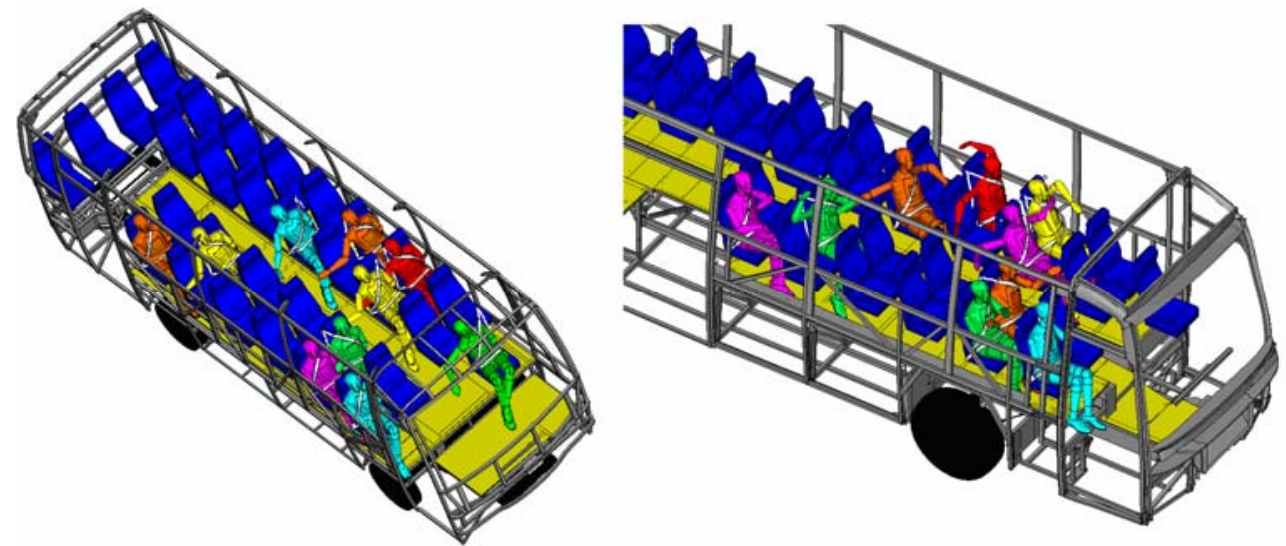

Figure 10: Rollover of the buses - three point safety belts

Tab. 3 - Max. values of the biomechanical loading of the dummies - three point safety belts

\begin{tabular}{|c|c|c|c|c|c|c|c|c|c|c|}
\hline \multicolumn{11}{|c|}{ Suburban bus } \\
\hline \multirow[t]{3}{*}{ Dummy } & \multicolumn{2}{|c|}{ Head } & \multicolumn{2}{|c|}{ Thorax } & \multicolumn{2}{|c|}{ Pelvis } & \multicolumn{4}{|c|}{ Belts } \\
\hline & \multirow[t]{2}{*}{$\begin{array}{l}\text { HIC1 } \\
5\end{array}$} & \multirow[t]{2}{*}{$\begin{array}{l}\text { time } \\
{[\mathrm{ms}]}\end{array}$} & \multirow{2}{*}{$\begin{array}{c}3 \mathrm{~ms} \\
\max \\
{[\mathrm{g}]}\end{array}$} & \multirow[t]{2}{*}{$\begin{array}{l}\text { time } \\
{[\mathrm{ms}]}\end{array}$} & \multirow{2}{*}{$\begin{array}{c}3 \mathrm{~ms} \\
\max \\
{[\mathrm{g}]}\end{array}$} & \multirow[t]{2}{*}{$\begin{array}{l}\text { time } \\
\text { [ms] }\end{array}$} & \multicolumn{2}{|c|}{ Shoulder part } & \multicolumn{2}{|c|}{$\begin{array}{c}\text { Abdomen } \\
\text { part }\end{array}$} \\
\hline & & & & & & & $\begin{array}{l}\text { force } \\
{[\mathrm{kN}]}\end{array}$ & $\begin{array}{l}\text { time } \\
{[\mathrm{ms}]}\end{array}$ & $\begin{array}{l}\text { force } \\
{[\mathrm{kN}]}\end{array}$ & $\begin{array}{l}\text { time } \\
{[\mathrm{ms}]}\end{array}$ \\
\hline \multirow{4}{*}{$\begin{array}{l}\text { Maximu } \\
\text { m values }\end{array}$} & 208 & 1651 & 33 & 1654 & 20 & 1726 & 2,135 & 2190 & 1,168 & 2130 \\
\hline & 100 & 1656 & 24 & 1869 & 13 & 1867 & 4,408 & 2120 & 2,125 & 2310 \\
\hline & 398 & 2087 & 18 & 2087 & 20 & 2070 & 2,544 & 2190 & 1,873 & 2110 \\
\hline & 100 & 1665 & 15 & 1738 & 21 & 1699 & 3,754 & 1700 & 1,559 & 1730 \\
\hline & \multicolumn{6}{|c|}{ Coach } & & & & \\
\hline \multirow[t]{3}{*}{ Dummy } & \multicolumn{2}{|c|}{ Head } & \multicolumn{2}{|c|}{ Thorax } & \multicolumn{2}{|c|}{ Pelvis } & \multicolumn{4}{|c|}{ Belts } \\
\hline & \multirow[t]{2}{*}{$\begin{array}{l}\text { HIC1 } \\
5\end{array}$} & \multirow[t]{2}{*}{$\begin{array}{l}\text { time } \\
{[\mathrm{ms}]}\end{array}$} & \multirow{2}{*}{$\begin{array}{c}3 \mathrm{~ms} \\
\max \\
{[\mathrm{g}]}\end{array}$} & \multirow[t]{2}{*}{$\begin{array}{l}\text { time } \\
\text { [ms] }\end{array}$} & \multirow{2}{*}{$\begin{array}{c}3 \mathrm{~ms} \\
\max \\
{[\mathrm{g}]}\end{array}$} & \multirow[t]{2}{*}{$\begin{array}{l}\text { time } \\
{[\mathrm{ms}]}\end{array}$} & \multicolumn{2}{|c|}{ Shoulder part } & \multicolumn{2}{|c|}{$\begin{array}{c}\text { Abdomen } \\
\text { part }\end{array}$} \\
\hline & & & & & & & $\begin{array}{l}\text { force } \\
{[\mathrm{kN}]}\end{array}$ & $\begin{array}{l}\text { time } \\
{[\mathrm{ms}]}\end{array}$ & $\begin{array}{l}\text { force } \\
{[\mathrm{kN}]}\end{array}$ & $\begin{array}{l}\text { time } \\
{[\mathrm{ms}]}\end{array}$ \\
\hline \multirow{3}{*}{$\begin{array}{l}\text { Maximu } \\
\text { m values }\end{array}$} & 549 & 1930 & 43 & 1986 & 31 & 1987 & 4,231 & 1940 & 2,038 & 1980 \\
\hline & 675 & 1829 & 88 & 1912 & 62 & 1918 & 3,544 & 1990 & 2,837 & 2030 \\
\hline & 490 & 1829 & 58 & 1829 & 77 & 1830 & 2,016 & 2090 & 1,835 & 1990 \\
\hline
\end{tabular}

\subsection{Disabled passengers}

Figure 11 presents the final positions of the rolled over city bus. The view is focused on the disabled passenger, who was belted in the left part and not belted in the right part of Figure 11. 

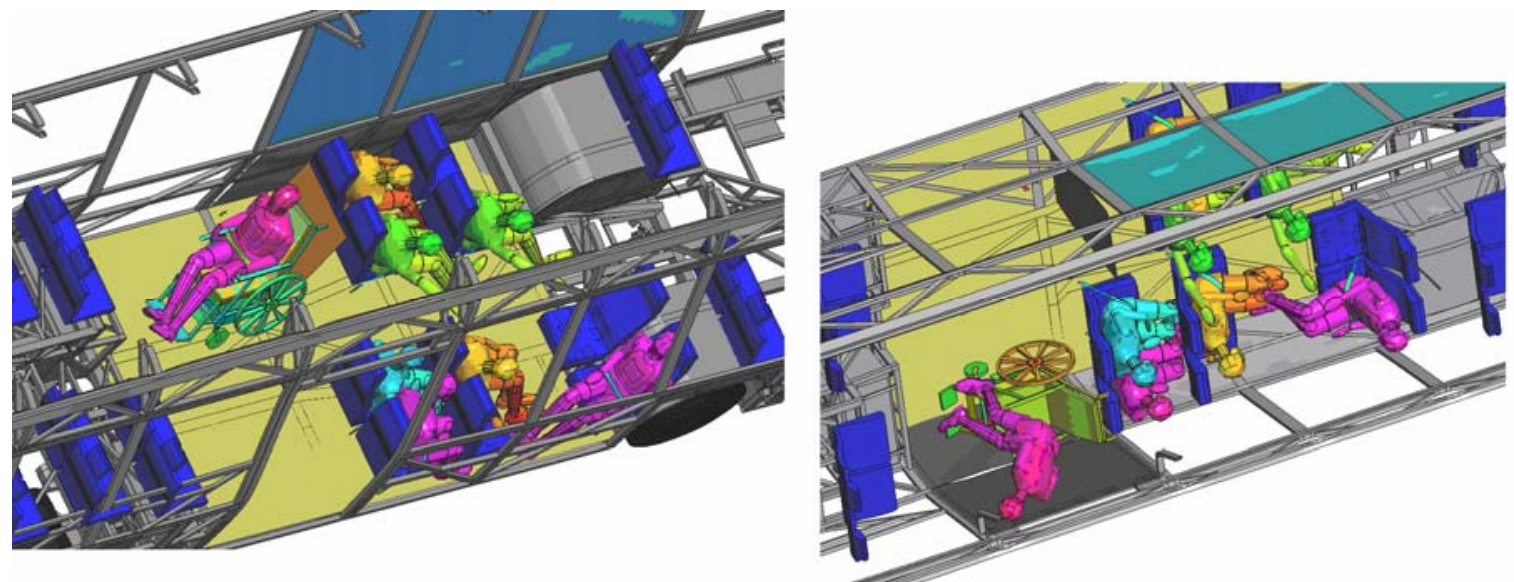

Figure 11: Rollover of the city bus focused on the disabled passenger (belted - unbelted)

The maximum values of the biomechanical loading of the disabled passenger are stated in Table 4. The peak value of the axial force is added to the relevant table.

Tab. 4 - Maximum values of the biomechanical loading of the disabled passenger.

\begin{tabular}{|c|c|c|c|c|c|c|c|c|}
\hline \multicolumn{9}{|c|}{ Unbelted disabled passenger } \\
\hline \multirow[t]{2}{*}{ Dummy } & \multicolumn{3}{|c|}{ Head } & \multicolumn{2}{|c|}{ Thorax } & \multicolumn{3}{|c|}{ Pelvis } \\
\hline & HIC1 & \multicolumn{2}{|c|}{$\begin{array}{l}\text { time } \\
\text { [ms] }\end{array}$} & $\begin{array}{c}3 \text { ms max } \\
{[\mathrm{g}]}\end{array}$ & $\begin{array}{l}\text { time } \\
{[\mathrm{ms}}\end{array}$ & \multicolumn{2}{|c|}{$\begin{array}{c}3 \text { ms max } \\
{[\mathrm{g}]}\end{array}$} & $\begin{array}{l}\text { time } \\
{[\mathrm{ms}]}\end{array}$ \\
\hline \multirow{2}{*}{$\begin{array}{c}\text { Maximum } \\
\text { values }\end{array}$} & 154 & \multicolumn{2}{|c|}{1165} & 47 & 116 & \multicolumn{2}{|c|}{22} & 1165 \\
\hline & \multicolumn{8}{|c|}{ Belted disabled passenger } \\
\hline \multirow[t]{2}{*}{ Dummy } & \multicolumn{2}{|c|}{ Head } & \multicolumn{2}{|c|}{ Thorax } & \multicolumn{2}{|c|}{ Pelvis } & \multicolumn{2}{|c|}{ Belt } \\
\hline & HIC15 & $\begin{array}{l}\text { time } \\
\text { [ms] }\end{array}$ & $\begin{array}{c}3 \mathrm{~ms} \\
\max \\
{[\mathrm{g}]}\end{array}$ & $\begin{array}{l}\text { time } \\
\text { [ms] }\end{array}$ & $\begin{array}{c}3 \mathrm{~ms} \\
\max \\
{[\mathrm{g}]}\end{array}$ & $\begin{array}{l}\text { time } \\
\text { [ms] }\end{array}$ & $\begin{array}{l}\text { force } \\
{[\mathrm{kN}}\end{array}$ & $\begin{array}{l}\text { time } \\
{[\mathrm{ms}]}\end{array}$ \\
\hline $\begin{array}{l}\text { Maximum } \\
\text { values }\end{array}$ & 10 & 1983 & 6 & 101 & 11 & 2008 & 5,09 & 2020 \\
\hline
\end{tabular}

\section{INTERPRETATION AND COMPARISON OF DUMMY LOADING VALUES}

The comparison of the rotational impact velocities of the monitored buses indicates that the lower the position of Center of gravity (COG) of the vehicle is, the lower the rotational impact velocity also is. The difference in the rotational impact velocities is approximately $13 \%$.

The values of the biomechanical criteria from the simulations with the belted and unbelted passengers were used to evaluate the influence of the restraint safety systems.

The behavior of the passengers during the rollover depends on the interior of the vehicle. High seat backrests in suburban bus and coach prevent passengers from moving across the vehicle. In the city bus the seats are placed lower and some of them may be turned backwards, unlike the seats in the suburban bus and coach. This allows the passengers to move through the entire width of the vehicle. 
Up to $25 \%$ higher HIC15 values were found on the unbelted passengers in the coach and suburban bus compared to the city bus. These values are mainly affected by the aforementioned higher rotational impact velocity. The maximum HIC15 values were reached by the contact between the head of the dummy and the interior of the vehicle.

According to the assumption the fixation of the passengers into the seats prevents them from hardly any definable motion across the bus. Owing to the passengers' fixation, the risk of leaving the vehicle during the crash is minimized. Most of the dummies did not interact with either the surrounding seats, the interior equipment, or the other dummies. This fact had a major affect on the observed values of the biomechanical loading of the passengers, which are significantly lower compared to those values measured in the simulation with unbelted passengers.

\section{CONCLUSIONS}

The values of the biomechanical criteria from the simulations with the unbelted passengers are mainly affected by the position of COG of the vehicle.

The conclusions of the performed simulations refer to a fact that the biomechanical criteria in the case of fixation of the passengers are affected mainly by the COG position of the vehicle and the influence of the vehicle type usage is not that significant. The decisive factor, which particularly affects the biomechanical loading values, is the interaction of the dummy with the surrounding objects (other dummies, window pillars, inner coating, seats, etc.).

The analysis was completed with the peak axial forces in the belts. The values of the axial belt forces in the suburban bus and the coach are approximately 30\% higher then the values measured in the belts applied in the city bus. It can be stated, that the axial belt force generally rises with the increasing position of COG. The highest value of the axial belt force was reached in the belt which held the disabled person (city bus), see Tab. 2 and 3.

The absolute values of the biomechanical criteria are affected by usage of the ARB HIII dummy model. This dummy model consists of rigid bodies connected by joint links. By the contact between the dummy and the vehicle chassis the recorded accelerations are notably higher then it would be in case of usage of the deformable dummy model. On the other hand, using the deformable dummy model would be excessively demanding for computation, as well as considerably more expensive.

\section{ACKNOWLEGMENTS}

The authors acknowledge the kind financial support of the Czech Ministry of Transport by the Project No. 1F54G/106/150.

\section{REFERENCES}

Actual version of the Regulation EHK R66, Regulation ES 2001/85.

TÜV UVMV technical reports related to EKH R66 test.

Technical report TÜV UVMV No. TECH - Z 12 / 2006.

Technical report TAC No. TECH-Z 14 / 2007 Analysis of the passengers - seats contact.

PSI, the Software Company of ESI Group; Pam-CRASH / Pam-Safe solver notes; 2007.

PSI, the Software Company of ESI Group; Pam-CRASH / Pam-Safe reference manual; 2007. 